\title{
Examining patient preferences in the treatment of rheumatoid arthritis using a discrete-choice approach
}

\author{
Rieke Alten' \\ Klaus Krüger ${ }^{2}$ \\ Julian Rellecke ${ }^{3}$ \\ Julia Schiffner-Rohe ${ }^{4}$ \\ Olaf Behmer ${ }^{5}$ \\ Guido Schiffhorst ${ }^{3}$ \\ Hans-Dieter Nolting ${ }^{3}$ \\ 'Schlosspark-Klinik, Charité, \\ University Medicine Berlin, \\ ${ }^{2}$ Praxiszentrum St Bonifatius, \\ Munich, ${ }^{3}$ GES Institut GmbH, ${ }^{4}$ Pfizer \\ Deutschland $\mathrm{GmbH}$, ${ }^{5}$ Pfizer Pharma \\ $\mathrm{GmbH}$, Berlin, Germany
}

This article was published in the following Dove Press journal:

Patient Preference and Adherence

I November 2016

Number of times this article has been viewed

Background: Biological disease-modifying antirheumatic drugs (bDMARDs) used in second-line treatment of rheumatoid arthritis (RA) are administered parenterally. However, so-called targeted synthetic DMARDs (tsDMARDs) - developed more recently - offer alternative (ie, oral) administration forms in second-line treatment. Since bDMARDs and tsDMARDs can be regarded as equal in terms of efficacy, the present study examines whether such characteristics as route of administration drive RA patients' treatment choice. This may ultimately suggest superiority of some second-line DMARDs over equally effective options, at least according to RA-patient preferences.

Objective: The current study assessed the importance of oral administration among other treatment characteristics differing between available second-line DMARDs for RA patients' preferences using a discrete-choice experiment (DCE).

Materials and methods: The DCE involved scenarios of three hypothetical treatment options in a $d$-efficient design with varying levels of key attributes (route and frequency of administration, time till onset of drug effect, combination therapy, possible side effects), as defined by focus groups. Further patient characteristics were recorded by an accompanying questionnaire. In the DCE, patients were asked to choose best and worst options (best-worst scaling). Results were analyzed by count analysis and adjusted regression analysis.

Results: A total of 1,588 subjects completed the DCE and were eligible for final analyses. Across all characteristics included in the DCE, "oral administration" was most desired and "intravenous infusion" was most strongly rejected. This was followed by "no combination with methotrexate" being strongly preferred and "intake every 1-2 weeks" being strongly rejected. On average, levels of route of administration showed strongest influences on patients' decisions in post hoc bootstrapping analysis.

Conclusion: According to the results, an oral DMARD that does not have to be combined with methotrexate and is not administered (only) every 1-2 weeks appears a highly favorable treatment option for patients with RA. DMARDs meeting these preferences may increase compliance and adherence in RA treatment.

Keywords: rheumatoid arthritis, disease-modifying antirheumatic drugs, patient preferences, discrete-choice experiment, best-worst scaling

\section{Introduction}

Rheumatoid arthritis (RA) is a chronic inflammatory autoimmune disease associated with multisystemic manifestations, characterized by persistent inflammatory synovitis of peripheral joints in symmetric distribution, which causes cartilage damage and bone erosion. ${ }^{1}$ In addition, RA patients display a variety of other clinical features,
Schlosspark-Klinik, Universitätsmedizin

Charité, 2 Heubnerweg, Berlin 14059,

Germany

Tel +49303264 I325

Email rieke.alten@schlosspark-klinik.de 
such as pain, morning stiffness, weakness, fatigue, fever, weight loss, and depression. ${ }^{2}$ The prevalence of RA varies by population, with Europe yielding prevalence rates between $0.32 \%$ in France and $0.89 \%$ in the $\mathrm{UK}^{3}$ and somewhat larger prevalence rates around $1 \%$ reported for the US. ${ }^{4}$ Typically, females are affected approximately two to three times more often than males. ${ }^{4,5}$ RA can occur at any age, but typically manifests between 40 and 70 years of age, ${ }^{2}$ with a peak of disease manifestation at 56 years of age in Germany. ${ }^{6}$

Pharmacological treatment of RA rests mainly on diseasemodifying antirheumatic drugs (DMARDs). These agents target altered inflammatory processes in RA, aiming to reduce symptoms of increased inflammation and associated negative outcomes, such as progression of joint damage, disability, impairment, and negative impact on quality of life. ${ }^{7}$ Like any disease-modifying medication, DMARDs have to be taken continuously to alter disease progression. Various DMARDs are available, differing with respect to the exact physiological processes they target. Such physiological differences constitute differences also in terms of more practical characteristics of the drugs, such as mode of administration (eg, oral, subcutaneous, and intravenous [IV]), frequency of administration (daily, weekly, monthly), or necessity to monitor blood values.

According to current treatment recommendations by both the European League Against Rheumatism (EULAR) ${ }^{7}$ and the American College of Rheumatology (ACR), ${ }^{8}$ two major classes of agents are suggested for second-line treatment of RA, ie, treatments that should be used if conventional DMARDs have failed: biologic (b)-DMARDs and targeted synthetic (ts)-DMARDs, with the latter developed more recently. ${ }^{7}$ Both bDMARDs and tsDMARDs show similar efficacy in clinical settings, ${ }^{8-10}$ but differ with respect to other potentially relevant characteristics: whereas bDMARDs are all administered parenterally, tsDMARDs are administered orally. This also comes with a more frequent intake of tsDMARDs relative to bDMARDs. In addition, some bDMARDs are recommended only in combination with methotrexate (MTX), while currently approved tsDMARDs can also be taken as monotherapy.

Importantly, practical characteristics of treatments, such as route or frequency of administration, may determine the convenience of drug intake and thereby impact on patients' compliance with prescribed treatments outside clinical settings. In other chronic diseases, there is evidence to suggest that parenteral modes of administration are associated with certain barriers perceived by patients, which in turn may lead to reduced adherence to prescribed treatments. ${ }^{11-13}$ Therefore, real-life efficacy of treatments will depend not only on their clinical efficacy but also on treatment characteristics impacting on patient adherence.

Since it has been recognized that patient preferences play an important role in adherence to prescribed medication, ${ }^{14-17}$ the patient perspective is increasingly important in assessing a therapy's value. Treatment regimens in line with patient preferences will be more likely associated with higher drug satisfaction and willingness to adhere to one's prescription, which will ultimately lead to higher real-life efficacy. In line with this reasoning, EULAR and ACR recommendations ${ }^{7,8}$ suggest a process of shared decision making between rheumatologists and patients, taking into account patient preferences when choosing a suitable medication.

To inform decision making, particularly with regard to the importance of oral administration for RA-patient preferences, a quantitative approach is needed, evaluating such characteristics within the framework of other key treatment characteristics that differ meaningfully between available second-line DMARD options. Initially, the present investigation used focus groups to establish which characteristics differing between tsDMARDs and bDMARDs generally mattered to RA patients (ie, aspects of route of administration, frequency of administration, time till onset of drug effect, combination therapy with MTX, and possible side effects). However, this technique was considered only for preliminary investigation, as it lacks the capability to quantify exactly the relative importance of treatment characteristics (eg, how much more or less important is oral relative to other forms of administration?).

Although there is a profound body of evidence regarding medication preferences in the RA-patient population, ${ }^{18}$ most studies have only elicited direct preference statements from patients, eg, by rating scales or rankings. ${ }^{19-24}$ With such methods, values assigned by respondents often violate certain statistical assumptions, which is likely due to confounding factors, such as limited attention or memory span. ${ }^{25}$ Therefore, just like focus groups, direct preference measurements represent a valid strategy to determine treatment characteristics that generally matter to patients, but are less suited to quantify the exact degree to which they matter.

More precise preference measures can be obtained by choice-based, indirect measurement techniques, ie, socalled discrete-choice experiments (DCEs), increasingly used in health care research. ${ }^{25}$ Instead of directly asking individuals to state their preferences, DCEs infer preferences based on choices. Individuals are asked to choose their preferred option among different (hypothetical) alternatives. Alternatives are composed of multiple "attributes" (eg, mode of administration) with varying "levels" (eg, oral, subcutaneous, IV). Typically, choices are repeated across orthogonally 
composed sets of alternatives, ie, alternatives in which levels of all attributes have been independently combined with one another. Due to repeated decisions in an orthogonal design, this procedure renders a less complex task (only a subset of levels is presented at a time for each decision) that is less prone to measurement errors and violation of statistical assumptions than direct preference statements. The exact influence of the varying levels on choices can be quantified through statistical modeling.

A special case of the DCE is so-called best-worst scaling (BWS). ${ }^{25,26}$ Other than traditional DCEs, BWS requires respondents not only to decide on the most preferred option but also to decide on the least preferred (worst) option, which renders richer information in less time. Moreover, subjects seem to make more consistent choices if they have to consider the extremes ("best" and "worst"), rather than having to choose only the best option. ${ }^{27}$

The current study attempted a precise quantification of RA-patient preferences by implementing a DCE with BWS. Attribute levels used in the DCE had been previously evaluated for their general importance in focus groups with RA patients.

\section{Materials and methods Study design \\ Setting}

This research was conducted as a questionnaire-based noninterventional study with patients treated by rheumatologists all over Germany. Questionnaires were sent to participating rheumatologists, who distributed them to patients meeting inclusion criteria and agreeing to participate. Patients returned their questionnaire by mail or completed an online version of the questionnaire. No personal information that would allow associating responses with an individual patient was recorded. Due to the lack of personal information, neither formal informed consent nor an ethic approval were necessary in accordance with the WMA Declaration on Ethical Considerations Regarding Health Databases and Biobanks, because this survey was not considered as intervention.

\section{Study population}

Based on the prevalence of approximately 440,000 RA patients in Germany, ie, $0.65 \%$ of the German population, ${ }^{28}$ we aimed to include at least 1,574 RA patients for final analyses to estimate patient preferences with high precision. Using this sample size, the quantity of any trait could be estimated with a sampling error of 5\% and a confidence interval (CI) of $95 \%$. The following inclusion criteria were to be met by patients: subjects had to be diagnosed with RA, at least 18 years of age, show a sufficient level of proficiency in the German language, and be treated with at least one DMARD.

\section{Choice of attributes and levels}

Discussions with focus groups were conducted to identify relevant DMARD attributes and their levels to be used in the final DCE. Separate focus groups took place in Munich and Berlin, Germany, including patients diagnosed with RA (Munich, $\mathrm{n}=12$; Berlin, $\mathrm{n}=8$ ).

An initial list of attributes and their levels based on available second-line DMARDs currently recommended by the EULAR ${ }^{7}$ and $\mathrm{ACR}^{8}$ was presented to participants at the outset of discussion. Effectiveness was excluded from discussion, as relevant second-line DMARDs do not differ in this respect. ${ }^{9,10}$ Patients were asked to add further important attributes they felt were missing to the list.

After discussion on why these attributes felt important and in how far their different levels presented a perceivable and meaningful difference, each patient was asked to rank attributes in order of their subjective importance. Based on these ranking results, the following attributes (and pertaining levels; see Table 1) were included in the DCE: "mode of administration", "frequency of administration", "time till onset of drug effect", "necessity of combination therapy", and "possible side effects". Table 1 lists relevant levels per attribute that were agreed to present a perceivable and meaningful difference, and thus were used for construction of the DCE.

\section{Questionnaire}

The main part of the questionnaire consisted of the DCE with eight scenarios (ie, decision cards), each presenting three hypothetical treatment alternatives with varying levels of the same attributes (multiprofile case or "case 3" design). Patients

Table I Attributes and levels used in the DCE/BWS

\begin{tabular}{ll}
\hline Attributes & Levels \\
\hline Route & Subcutaneous self-injection \\
of administration & $\begin{array}{l}\text { Intravenous infusion } \\
\text { Oral intake (pill) } \\
\text { Twice daily }\end{array}$ \\
Frequency & Once every I-2 weeks \\
of administration & Once every 4-8 weeks \\
& Once every 6-I2 months \\
Time till onset of & Up to I month \\
drug effect & More than I month up to 3 months \\
Combination therapy & Treatment requires administration of MTX \\
& once a week \\
Possible side effects & No combination necessary \\
& Infections \\
& Allergic reactions \\
& Deterioration of laboratory values
\end{tabular}

Abbreviations: DCE, discrete-choice experiment; BWS, best-worst scaling; MTX, methotrexate. 
Table 2 Example of a decision card (DCE scenario) used in the questionnaire

\begin{tabular}{llll}
\hline Attribute & Treatment I & Treatment $\mathbf{~}$ & Treatment 3 \\
\hline Route of administration & Subcutaneous self-injection & Intravenous infusion & Pill \\
Frequency of administration & Once every 6-I2 months & Once every I-2 weeks & Twice daily \\
Time till onset of drug effect & Up to I month & More than I month up to 3 months \\
MTX combination therapy & MTX once a week & No MTX combination necessary & M month \\
Possible side effects & Infections & Allergic reactions & Deterioration of laboratory values \\
Treatment I like best & $\square$ & $\square$ & $\square$ \\
Treatment I find worst & $\square$ & $\square$ & $\square$
\end{tabular}

Abbreviations: DCE, discrete-choice experiment; MTX, methotrexate.

were asked to choose the best and worst treatment options on each decision card, ie, each respondent had to make eight "best" and eight "worst" choices. Table 2 gives an example of a decision card used in the questionnaire.

For the DCE, attribute levels were combined in a $d$-efficient design using the Fedorov algorithm. ${ }^{29}$ The $d$-efficient approach retains optimal orthogonality in a fractional design while excluding unrealistic level combinations (ie, "infusion, two times daily" and "oral intake, once every 6-12 months") and reducing the number of necessary combinations relative to a full orthogonal design. The initially required 16 decision cards (scenarios) for an optimal design were considered too taxing for patients, so cards were equally divided across two otherwise-identical versions of the questionnaire (blocked design), resulting in eight BWS scenarios per questionnaire (subject). Blocked designs have been shown to increase response efficiency and thus the validity of DCE results. ${ }^{30}$ The remainder of the questionnaire consisted of items on sociodemographic and disease-/treatment-related patient characteristics, as well as an assessment on beliefs about medicine.

To secure anonymity of data, age of participants, duration of symptoms, and onset of RA (disease duration) were recorded in categories. Categorization of duration of symptoms and onset of RA (disease duration) allowed for differentiation between early RA ( $<2$ years) and established RA ( $\geq 10$ years). Disease activity was assessed using the Rheumatoid Arthritis Disease Activity Index (RADAI)-5, ${ }^{31,32}$ offering a validated quick self-assessment of RA activity.

To derive experience with injectables, patients were asked to provide information on their DMARD medication. In addition, patients were asked to report whether they were currently receiving injectables for other diseases. Satisfaction with efficacy and tolerability of current DMARD medication were each rated by patients on a 5-point Likert scale. Beliefs about current DMARD treatment were assessed using a modified version of the Beliefs about Medicines Questionnaire (BMQ). ${ }^{33-35}$

\section{Data analysis}

\section{Patient variables}

For all sociodemographic and disease-/treatment-related variables, absolute and relative frequencies were calculated (n, \%). The RADAI-5 score was calculated as the mean across the five items of the instrument (each evaluated on a 10-point Likert scale ranging from $1=$ "not at all active" to $10=$ "extremely active"), with mean scores $\leq 1.4$ indicating remission-like, 1.6-3 mild, 3.2-5.4 moderate, and 5.6-10 high disease activity. ${ }^{32,36}$

For the modified BMQ, item values ( $1=$ "disagree", $2=$ "uncertain", or 3= "agree") were added separately for items capturing "necessity" toward current DMARD treatment (three items) and "concern" (six items), with sums $\leq 6(>6)$ indicating low (high) necessity and sums $<12(\geq 12)$ indicating low (high) concern. Moreover, based on their responses in the BMQ, patients were classified according to the necessityconcern framework, as presented in Table $3 .{ }^{37}$

For analysis, patient responses on the 5-point Likert scales regarding drug satisfaction (efficacy and tolerability of current DMARD medication) were recategorized into "not satisfied" (including values of $1=$ "not at all satisfied" and $2=$ "not satisfied"), "neither" (value of 3 ), and "satisfied" (including values of $4=$ "satisfied" and 5= "very satisfied").

\section{Preference data (DCE)}

Data from the DCE was analyzed by both count analysis ${ }^{38}$ and regression analysis. ${ }^{25}$ While count analysis offers an easily accessible and interpretable method to infer the relative importance of attribute levels for patient choices, (adjusted) regression analysis allows the assessment of statistical significance of their importance while controlling for potential confounders (ie, sociodemographic and disease-/treatmentrelated variables).

Table 3 Classification according to necessity-concern framework

\begin{tabular}{lll}
\hline & Low necessity & High necessity \\
\hline Low concern & Indifferent & Accepting \\
High concern & Skeptical & Ambivalent \\
\hline
\end{tabular}


Count analysis is solely based on frequencies of BW choices. The importance of an attribute level is calculated as the difference between percentages of the level being included in treatment options chosen as "best" minus percentages of the level being included in options chosen as "worst" across all choices. Positive BW scores indicate an attribute level to be predominantly associated with "best" choices; conversely, negative BW scores indicate it to be predominantly associated with "worst" choices. In contrast, BW scores near 0 indicate levels that are either chosen less often or chosen as best and worst similarly often, indicating levels that do not contribute to choices (ie, are meaningless in terms of patient preferences). Higher absolute values of BW scores thus reflect a stronger influence of an attribute level on choices; ordering BW scores according to their absolute values gives a ranking of levels in terms of their importance for patient preferences..$^{27,38,39}$

For regression analysis, the paired-model approach of Flynn et $\mathrm{al}^{25}$ was used. The dependent variable in this model is the natural log of the total number of times a particular BW pair is chosen across scenarios (ie, a particular level chosen best with another particular level chosen worst), adjusted for the total number of times the pair was presented (number of scenarios $\times$ number of participants). Adjusted counts are modeled with a linear weighted-least-squares model. Attribute levels are entered as effect-coded explanatory variables (value $=1$ if coded level is chosen best, value $=-1$ if coded level is chosen worst, value $=0$ if coded level is not chosen). Derived $\beta$-weights reflect the rate of change from the expected choice frequency (ie, if all choices were made randomly) implied by a level, which is interpreted as the utility of that level. ${ }^{25,40}$ Positive $\beta$-values indicate deviations toward "best" decisions, and negative $\beta$-values indicate deviations toward "worst" decisions.

The final model involved an adjusted regression analysis including all sociodemographic and disease-/treatment-related variables (patient variables age, sex, onset of RA, duration of symptoms, route of current DMARD administration, any current injectable, RADAI-5, BMQ classification, satisfaction with efficacy/tolerability) as effect-coded covariates (value $=1$ if coded category is present, value $=0$ if coded category is not present). Since in the final model, $\beta$-weights of effect-coded covariates correspond to deviations from the grand mean, higher absolute values indicate that in a given group of patients (eg, females) choices of some BW pairs occur either less often (negative $\beta$-weight) or more often (positive $\beta$-weight) than would be expected from the grand mean across all patients (ie, if all patients made the same choices).
The final equation of the model is as follows. Note that in effect coding one level (category) per attribute (variable) is omitted and used as reference (we used levels with the lowest BW scores per attribute from count analysis as references; for ordinal covariates, the lowest category per variable was chosen; for nominal variables an arbitrary reference category was used):

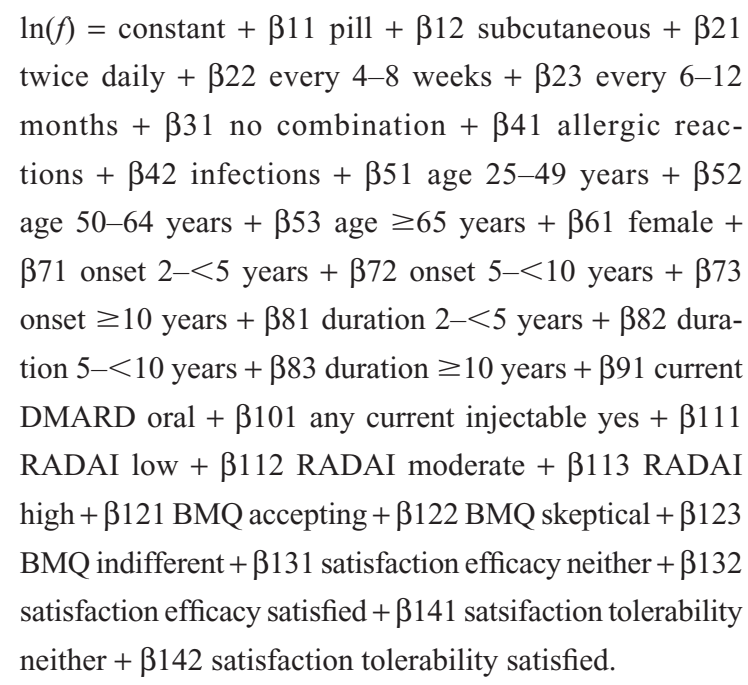

In the DCE design (multiprofile case or "case 3" design), patients had to choose whole options consisting of varying level combinations while key attributes were kept constant. The relative importance of the attributes for patient choices would thus be a mere function of their levels' importance; there was no independent contribution of attributes per se to the participants' choices that could be defined in the regression model (for a different design, see Flynn et $\mathrm{al}^{25}$ ).

\section{Post hoc bootstrapping analysis}

An estimate of the attributes' relative importance was derived by calculating the mean maximum span between the levels' regression coefficients per attribute (ie, difference between $\beta$-values of the most favored and the least favored level of an attribute) from 1,000 bootstrap samples. Adjusted regression and the maximum span between levels' $\beta$-values per attribute (relative importance) were recalculated for each bootstrap sample to determine the attributes' mean relative importance (mean maximum span) and their $95 \%$ CIs (percentiles 2.5 and 97.5 of the resulting distribution).

\section{Results \\ Sample data}

Patients were recruited from 44 rheumatologic practices across Germany, corresponding to $4 \%$ of German practitioners subspecialized in rheumatology. ${ }^{41}$ All participating physicians were specialists in internal medicine. The majority of patients 
were female (74\%), 50-64 years of age (45\%), reported less than 10 years of disease duration (55\%), mild-to-moderate disease activity (63\%), and were receiving some injectable DMARD (54\%); considering other medication also, overall 57\% were currently receiving some injectable (for details, see Table 4).

According to the modified BMQ, most patients were classified as "accepting" toward their medication (patients associating their medication with high necessity and low concern). This was also reflected by the majority of the patients being satisfied with the efficacy and tolerability of

Table 4 Distribution of sociodemographic and disease-/treatmentrelated variables

\begin{tabular}{|c|c|}
\hline Category & $\begin{array}{l}\text { Frequency, } \\
\text { n (\%) }\end{array}$ \\
\hline \multicolumn{2}{|l|}{ Age, years } \\
\hline $18-24$ & $15(0.9)$ \\
\hline $25-29$ & $26(1.6)$ \\
\hline $30-34$ & $42(2.6)$ \\
\hline $35-39$ & $49(3.1)$ \\
\hline $40-44$ & $104(6.5)$ \\
\hline $45-49$ & $150(9.4)$ \\
\hline $50-54$ & $222(14)$ \\
\hline $55-59$ & $217(13.7)$ \\
\hline $60-64$ & $267(16.8)$ \\
\hline $65-69$ & $177(11.1)$ \\
\hline$\geq 70$ & $312(19.6)$ \\
\hline \multicolumn{2}{|l|}{ Sex } \\
\hline Female & $\mathrm{I}, 168(73.5)$ \\
\hline Male & $345(21.7)$ \\
\hline \multicolumn{2}{|c|}{ Onset of RA (time of diagnosis) } \\
\hline$\leq 2$ years ago & $176(11.1)$ \\
\hline$\geq 2<5$ years ago & $302(19)$ \\
\hline$\geq 5<10$ years ago & $399(25.1)$ \\
\hline$\geq 10$ years ago & $700(44.1)$ \\
\hline \multicolumn{2}{|c|}{ Duration of symptoms } \\
\hline$\leq 2$ years & II 8 (7.4) \\
\hline$\geq 2<5$ years & $281(17.7)$ \\
\hline$\geq 5<10$ years & $389(24.5)$ \\
\hline$\geq 10$ years & $790(49.7)$ \\
\hline \multicolumn{2}{|l|}{ RADAI-5 } \\
\hline Remission-like & $294(18.5)$ \\
\hline Mild & $462(29.1)$ \\
\hline Moderate & $534(33.6)$ \\
\hline High & $236(14.9)$ \\
\hline \multicolumn{2}{|c|}{ Current mode of DMARD administration ${ }^{\mathrm{a}}$} \\
\hline Injectable & $863(54.4)$ \\
\hline Oral only & $683(43)$ \\
\hline \multicolumn{2}{|c|}{ Any current injectable ${ }^{b}$} \\
\hline Yes & $902(56.8)$ \\
\hline No & $639(40.2)$ \\
\hline Total & $1,588(100)$ \\
\hline
\end{tabular}

Notes: "Based on current DMARD treatment with its exact mode of administration; bbased on current DMARD treatment with its exact mode of administration and other current medication being received due to any comorbid diseases. Missing values per variable not shown.

Abbreviations: RA, rheumatoid arthritis; RADAl, Rheumatoid Arthritis Disease Activity Index; DMARD, disease-modifying antirheumatic drug.
Table 5 Distribution of modified BMQ classification and drug satisfaction

\begin{tabular}{ll}
\hline Category & $\begin{array}{l}\text { Frequency, } \\
\text { n (\%) }\end{array}$ \\
\hline Modified BMQ & \\
Necessity & \\
Low & $103(6.5)$ \\
High & $1,45 \mathrm{I}(91.4)$ \\
Concern & \\
Low & $1,079(67.9)$ \\
High & $356(22.4)$ \\
Classification & \\
Ambivalent & $319(20.1)$ \\
Accepting & $1,014(63.9)$ \\
Skeptical & $34(2.1)$ \\
Indifferent & $56(3.5)$ \\
Drug satisfaction & \\
Efficacy & \\
Unsatisfied & \\
Neither & $97(6.1)$ \\
Satisfied & $138(8.7)$ \\
Tolerability & $1,334(84)$ \\
Unsatisfied & \\
Neither & $119(7.5)$ \\
Satisfied & $121(7.6)$ \\
Total & $1,327(83.6)$ \\
\hline Notes:Bsed & $1,588(100)$ \\
\hline
\end{tabular}

Notes: aBased on low/high necessity and concern combinations; high-necessity-highconcern combinations indicate ambivalent, high-necessity-low-concern combinations indicate accepting, low-necessity-high-concern combinations indicate skeptical, and low-necessity-low-concern combinations indicate indifferent patients. ${ }^{37}$ Missing values per variable not shown.

Abbreviation: BMQ, Beliefs about Medicines Questionnaire.

their current treatment (see Table 5). However, a considerable percentage of the sample (20.1\%) was classified as having an "ambivalent" attitude toward their treatment (high necessity and high concern).

\section{Preference data}

\section{Count analysis}

Results from count analysis can be seen in Table 6. Based on absolute values of the BW scores, it can be suggested that choices were influenced most strongly by pill $(0.285)$, IV infusion (-0.24), combination with MTX $(-0.176)$, and intake every $1-2$ weeks $(-0.175)$. Therefore, options characterized by oral intake were most strongly preferred, whereas options entailing IV infusion, combination therapy with MTX, and intake once every week or second week were most strongly rejected.

\section{Adjusted regression analysis}

Figure 1 shows results of adjusted regression analysis for $\beta$-values of the attribute levels. The $\beta$-values of confounders (plus constant) are given separately in Table 7, as their values cannot be directly compared with those of the attribute levels (ie, different effect codes were used with values of 1 and -1 for best and worst choices, respectively, vs a value of 1 if 
Table 6 Results of count analysis

\begin{tabular}{|c|c|c|c|c|c|}
\hline \multirow[t]{2}{*}{ Attribute (levels) } & \multicolumn{2}{|c|}{ Chosen best } & \multicolumn{2}{|c|}{ Chosen worst } & \multirow[t]{2}{*}{ BW score } \\
\hline & Frequency & $\%$ & Frequency & $\%$ & \\
\hline \multicolumn{6}{|l|}{ Mode of administration } \\
\hline IV infusion & $2,78 \mid$ & 21.9 & 5,832 & 45.9 & -0.24 \\
\hline Pill & 6,234 & 49.1 & 2,617 & 20.6 & 0.285 \\
\hline SC self-injection & 3,689 & 29 & 4,255 & 33.5 & -0.045 \\
\hline \multicolumn{6}{|l|}{ Administration frequency } \\
\hline Twice daily & 2,633 & 36.6 & 2,208 & 30.7 & 0.059 \\
\hline Every I-2 weeks & 2,794 & 23.5 & 4,877 & 41 & -0.175 \\
\hline Every 4-8 weeks & 4,489 & 40.4 & 3,340 & 30 & 0.103 \\
\hline Every 6-12 months & 2,788 & 35.2 & 2,279 & 28.8 & 0.064 \\
\hline \multicolumn{6}{|l|}{ Combination therapy } \\
\hline Combination with MTX & 4,168 & 22.8 & 7,382 & 40.5 & -0.176 \\
\hline \multicolumn{6}{|l|}{ Possible side effects } \\
\hline Laboratory values & 3,303 & 26 & 5,038 & 39.7 & -0.137 \\
\hline Allergic reactions & 5,180 & 40.8 & 3,461 & 27.2 & 0.135 \\
\hline Infections & 4,221 & 33.2 & 4,205 & 33.1 & 0.001 \\
\hline \multicolumn{6}{|c|}{ Time till onset of drug effect } \\
\hline Up to I month & 7,542 & 36.6 & 6,426 & 31.2 & 0.054 \\
\hline Up to 3 months & 5,162 & 29.5 & 6,278 & 35.9 & -0.064 \\
\hline
\end{tabular}

Notes: BW scores correspond to difference of percentage. An attribute level was included in treatment options chosen as best minus percentage; it was included in options chosen as worst across all times of presentation (eg, IV infusion: $21.9 \%-45.9 \%=0.219-0.459=-0.24$ ). A positive BW score indicates an attribute level to be predominantly favored by patients; conversely, a negative BW score indicates a dislike of the level, and a BW score near 0 indicates that the level did not play a marked role in patients' choice. Abbreviations: BW, best-worst; IV, intravenous; SC, subcutaneous; MTX, methotrexate.

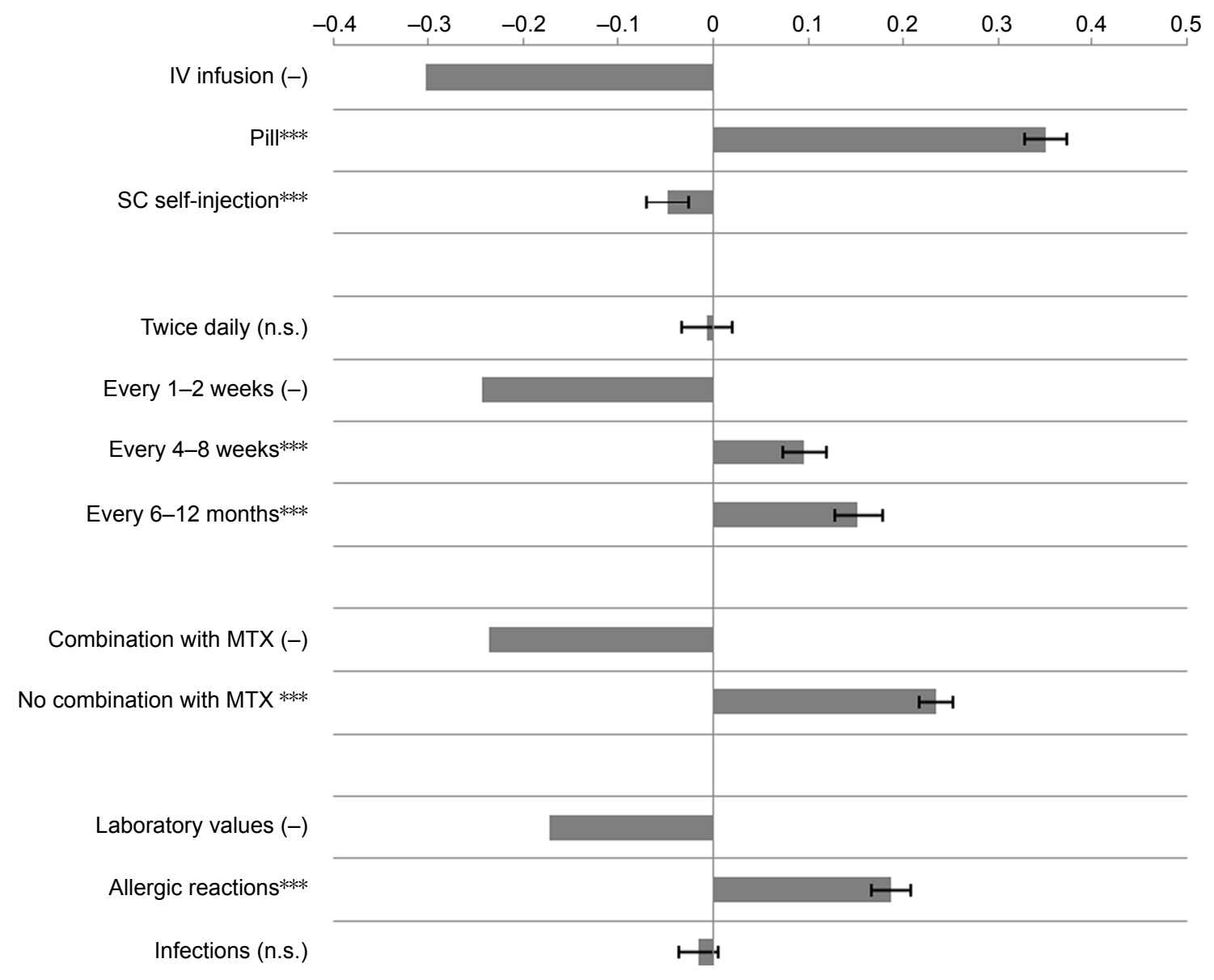

Figure I Results of adjusted regression analysis (attribute levels).

Notes: $* * * P<0001$. No $P$-values or $\mathrm{Cls}$ (lower/upper bound) computed for reference levels from effect coding. Reference levels in effect coding are indicated by (-). Attribute levels' positive $\beta$-weights reflect biases toward "best" choices and negative $\beta$-weights reflect biases toward "worst" choices.

Abbreviations: n.s., not significant; $\mathrm{Cl}$, confidence interval. 
Table 7 Results of adjusted regression analysis (patient variables)

\begin{tabular}{|c|c|c|c|c|}
\hline \multirow{2}{*}{$\begin{array}{l}\text { Attributes } \\
\text { (levels) }\end{array}$} & \multirow[t]{2}{*}{$\beta$-weight } & \multirow[t]{2}{*}{$P$-value } & \multicolumn{2}{|c|}{$95 \% \mathrm{Cl}$} \\
\hline & & & $\begin{array}{l}\text { Lower } \\
\text { bound }\end{array}$ & $\begin{array}{l}\text { Upper } \\
\text { bound }\end{array}$ \\
\hline Intercept & 1.005 & $<0.0001$ & 0.991 & 1.020 \\
\hline \multicolumn{5}{|l|}{ Patient variables } \\
\hline \multicolumn{5}{|l|}{ Age } \\
\hline$<25$ years & -0.337 & & & \\
\hline $25-49$ years & 0.017 & 0.005 & 0.005 & 0.030 \\
\hline $50-64$ years & 0.165 & $<0.0001$ & 0.153 & 0.176 \\
\hline $65+$ years & 0.155 & $<0.0001$ & 0.142 & 0.167 \\
\hline \multicolumn{5}{|l|}{ Sex } \\
\hline Male & -0.125 & & & \\
\hline Female & 0.125 & $<0.0001$ & 0.119 & 0.131 \\
\hline \multicolumn{5}{|l|}{ Onset of RA } \\
\hline$<2$ years ago & -0.263 & & & \\
\hline $2<5$ years ago & -0.123 & $<0.0001$ & -0.135 & -0.111 \\
\hline $5<10$ years ago & -0.012 & 0.054 & -0.024 & 0.0002 \\
\hline$\geq 10$ years ago & 0.397 & $<0.0001$ & 0.382 & 0.413 \\
\hline \multicolumn{5}{|c|}{ Duration of symptoms } \\
\hline$<2$ years & 0.029 & & & \\
\hline $2<5$ years & 0.082 & $<0.0001$ & 0.069 & 0.096 \\
\hline $5<10$ years & 0.012 & 0.066 & -0.001 & 0.024 \\
\hline$\geq 10$ years & -0.123 & $<0.0001$ & -0.139 & -0.108 \\
\hline \multicolumn{5}{|c|}{ DMARD administration } \\
\hline Injectable & 0.298 & & & \\
\hline Oral only & -0.298 & $<0.0001$ & -0.312 & -0.284 \\
\hline \multicolumn{5}{|c|}{ Any current injectable } \\
\hline Yes & 0.242 & & & \\
\hline No & -0.242 & $<0.0001$ & -0.256 & -0.229 \\
\hline \multicolumn{5}{|l|}{ RADAI-5 } \\
\hline Remission-like & 0.029 & & & \\
\hline Low & 0.11 & $<0.0001$ & 0.101 & 0.119 \\
\hline Moderate & -0.007 & 0.111 & -0.015 & 0.002 \\
\hline High & -0.132 & $<0.0001$ & -0.142 & -0.122 \\
\hline \multicolumn{5}{|c|}{ Categorization (BMQ) } \\
\hline Ambivalent & -0.005 & & & \\
\hline Accepting & 0.258 & $<0.0001$ & 0.248 & 0.268 \\
\hline Skeptical & -0.086 & $<0.0001$ & -0.105 & -0.066 \\
\hline Indifferent & -0.168 & $<0.0001$ & -0.185 & -0.15 \\
\hline \multicolumn{5}{|c|}{ Satisfaction with efficacy } \\
\hline Unsatisfied & -0.078 & & & \\
\hline Neither & -0.089 & $<0.0001$ & -0.100 & -0.079 \\
\hline Satisfied & 0.167 & $<0.0001$ & 0.158 & 0.176 \\
\hline \multicolumn{5}{|c|}{ Satisfaction with tolerability } \\
\hline Unsatisfied & -0.11 & & & \\
\hline Neither & -0.113 & $<0.0001$ & -0.124 & -0.102 \\
\hline Satisfied & 0.223 & $<0.0001$ & 0.215 & 0.232 \\
\hline
\end{tabular}

Notes: No $P$-values or Cls (lower/upper bound) computed for reference categories from effect coding. Reference categories in effect coding for patient variables were the following: $<25$ years (age), male, $<2$ years (onset of RA and duration of symptoms), injectable (current mode of DMARD administration), yes (any current injectable), remission-like, ambivalent (BMQ categorization), and unsatisfied (satisfaction with efficacy and tolerability). Positive $\beta$-values indicate best-worst pairs chosen more often and negative $\beta$-values best-worst pairs chosen less often than would be expected if all best-worst pairs were chosen equally often by all patients.

Abbreviations: RA, rheumatoid arthritis; DMARD, disease-modifying antirheumatic drug; RADAl, Rheumatoid Arthritis Disease Activity Index; BMQ, Beliefs about Medicines Questionnaire; $\mathrm{Cl}$, confidence interval.
Table 8 Mean relative importance of attributes and $95 \% \mathrm{Cl}$

\begin{tabular}{|c|c|c|c|}
\hline \multirow[t]{2}{*}{ Attribute } & \multirow{2}{*}{$\begin{array}{l}\text { Mean relative } \\
\text { importance }\end{array}$} & \multicolumn{2}{|c|}{$95 \% \mathrm{Cl}$} \\
\hline & & $\begin{array}{l}\text { Lower } \\
\text { bound }\end{array}$ & $\begin{array}{l}\text { Upper } \\
\text { bound }\end{array}$ \\
\hline $\begin{array}{l}\text { Route of administration } \\
\text { with MTX }\end{array}$ & 0.653 & 0.611 & 0.693 \\
\hline Combination therapy & 0.471 & 0.438 & 0.504 \\
\hline Frequency of administration & 0.396 & 0.357 & 0.436 \\
\hline Possible side effects & 0.361 & 0.326 & 0.398 \\
\hline Time till onset of drug effect & 0.186 & 0.150 & 0.221 \\
\hline
\end{tabular}

Abbreviations: $\mathrm{Cl}$, confidence interval; MTX, methotrexate.

category of a covariate was present; for different interpretations of $\beta$-values, see notes below Figure 1 and Table 7).

\section{Mean relative importance}

Table 8 gives the results of the post hoc bootstrapping analysis. On average, levels of route of administration were associated with largest differences between lowest and highest $\beta$-weights (highest mean relative importance). This was followed by (in descending order): combination therapy with MTX, frequency of administration, possible side effects, and time till onset of drug effect. Notably, none of the attributes' CIs overlapped with zero.

\section{Summary of results}

On average, levels of route of administration influenced choices most strongly. This was followed by combination therapy, frequency of administration, possible side effects, and time till onset of drug effect (in this order). None of the attributes' CIs overlapped with 0 . As such, on average, all attributes were important for patients' choices, though to a significantly different degree.

Patient choices, as yielded from count as well as regression analysis, were most influenced by clear preference of oral administration (pill) and rejection of IV infusion. These most important levels were followed (in descending order) by: rejection of "administration every 1-2 weeks", rejection of "combination with MTX", and acceptance of "allergic reactions" as possible side effects. Less pronounced influences were found for "subcutaneous self-injection" (rejected) and administration "every 6-12 months" or "every 4-8 weeks" (both preferred). Administration frequency of "twice daily" and "infections" as side effects did not matter for patients' choice.

\section{Discussion}

The present study aimed to determine the relative importance of DMARD characteristics for RA-patient preferences. This was achieved by using the well-established technique of a DCE. We used two different approaches to analyze choices 
made by RA patients in the DCE: simple count analysis and more refined adjusted regression analysis. The order of the attribute levels' importance as defined by count analysis was almost entirely reflected by sizes of the levels' regression weights ( $\beta$-values) in regression analysis. Slight differences were certainly due to a more precise modeling approach with adjusted regression analysis.

The impact of "pill" on choices outperformed that of all other attribute levels. It may thus be concluded that this feature drove patients' choices most decisively, representing the most important and desired treatment characteristic in our study. Further important levels for treatment decision were (in descending order): administration "every 1-2 weeks" and "combination with MTX" being rejected ("no combination with MTX" being preferred), and "allergic reactions" being most accepted possible side effects. Our results suggests a nonlinear, U-shaped relation between patients' choices and frequency of administration with indecisive attitude to high frequency of intake (twice daily), rejection of medium frequencies (every 1-2 weeks), and preference for low frequencies (every 6-12 months or every 4-8 weeks).

Besides twice-daily administration, as chosen in our study, once-daily administration may be considered a relevant frequency, especially for oral drug administration. We chose twice daily for several reasons. Levels were pretested in focus groups; if focus group members had mentioned a potential influence on patient preferences by differentiating between once and twice daily, this would have been included as a separate level in our study design. Further, the aim of our study was a setting of features typical of second-line treatment of RA with DMARDs. At the time of the study's design, there was no once-daily treatment available. Moreover, we assumed twice-daily administration as perceived to be "worse" to once-daily administration, allowing the conclusion that once-daily administration would be even better.

Regression analysis revealed that preferences persisted even when controlled for potential influences from patient characteristics (covariates, eg, age, sex). Therefore, the attribute levels' influences on choices reflect a more general nature of RA-patient preferences independently of individual patient characteristics. The strength of our study lies in the fact that included attribute levels were derived from available second-line DMARDs, thus presenting realistic treatment characteristics and increasing the ecological validity of our study. In addition, attribute levels had been previously checked for their general importance in focus groups, assuring that only treatment characteristics that really mattered to patients were included. Moreover, the DCE consisted of a so-called case 3 design involving scenarios with different multiattribute-treatment options presented to patients in parallel. This guaranteed a more realistic task, ie, it increased the ecological validity of our study, as patients would be presented with multiattribute treatments in the real world too.

The age and sex distribution of our sample was almost identical to data from the German Rheumatism Research Center, representing the most comprehensive register on the RA-patient population in Germany. ${ }^{6}$ Sample characteristics thus suggest a rather representative sample of the German RA population.

However, there are also certain limitations to our study. We included only outpatients, and thus cannot know how far results can be generalized to hospitalized patients as well. Moreover, although patient characteristics suggest a representative sample, we had no control over patient selection or dropouts, and thus our study probably did not include a random sample but was biased toward more motivated and compliant patients. In general, self-reports by patients may render high validity of preference data, but we had no means to check up on the validity of medically relevant information, such as current medication. Similarly, disease activity was assessed only by a validated self-assessment tool (RADAI-5), which shows sufficient correlation with clinical parameters, but cannot be taken as their equivalent.

With regard to our findings in light of previous research, at the time our study was conducted, to our knowledge there were only three studies assessing patient preferences toward DMARDs using a DCE approach that had been published in peer-reviewed journals, ${ }^{42-44}$ although none used BWS. While Skjoldborg et $\mathrm{al}^{42}$ did not include any levels of "route of administration" in their experiment and focused on a different research question, Poulos et $\mathrm{al}^{44}$ included only "injection at home" and "infusion at doctor's site", and thus neither considered all relevant characteristics of route of administration for currently available options in second-line treatment.

Augustovski et $\mathrm{al}^{43}$ were the only ones to include oral administration in their DCE. Similarly to our results, they demonstrated a preference for pills over parenteral (IV) routes of administration in RA patients. Our findings are thus generally in line with their study, ${ }^{43}$ and add to similar findings with other diseases using different methodologies. ${ }^{11-13}$ However, the ability of Augustovski et $\mathrm{al}^{43}$ to quantify exactly the relative importance of oral administration was limited, due to the coding procedure they used.

Our finding of a strong rejection of IV infusion is in line with previous reports on RA-patient preferences using 
other approaches than DCE. ${ }^{18}$ On the contrary, it has been reported that combination therapy with MTX is usually well accepted by RA patients, ${ }^{18,21,22}$ and thus our results suggesting a preference for monotherapy may seem contradictory. Previous studies did not assess combination therapy within the framework of other relevant (second-line) DMARD attributes though. We want to emphasize that our results are not intended to change any existing second-line treatment algorithms with currently available bDMARDs that mainly include combination with MTX. Nevertheless, patients' preference for monotherapy should be considered for future treatment options, which may not need to be combined with MTX in order to achieve and maintain maximal efficacy.

With regard to frequency of administration, Poulus et $\mathrm{al}^{44}$ reported RA patients to prefer treatment options to be taken in lower frequencies, unlike the "U-shaped" relationship we found. However, the highest frequency of administration in Poulus et $\mathrm{al}^{44}$ was "two treatments every week", which corresponds to our second-highest frequency level ("every 1-2 weeks"). Without a daily frequency level in our design, which was necessary by also including oral second-line treatments, preferences would probably have increased linearly with lower frequencies in our study as well. Therefore, our findings seem in line with those by Poulos et al. ${ }^{44}$

However, findings by Augustovski et al, ${ }^{43}$ who used frequencies of administration that resembled our levels more closely (eg, "every day" as highest frequency) clearly contradict our findings. However, methodological differences between their study and ours could explain these divergent findings: while we excluded unrealistic level combinations (such as twice-daily infusions), Augustovski et al included all theoretically possible combinations in their design. In fact, a highly implausible combination was even used as reference case ("an oral agent taken every 10 months"), which has been previously noted to interfere with reasonable trade-offs. ${ }^{30}$ Moreover, Augustovski et $\mathrm{al}^{43}$ included some entirely different attributes than our study, ie, cost and efficacy. Cost was not used in our DCE, as this attribute would be difficult to judge by our sample (in the German health care system, patients do not need to pay their RA treatment out of pocket); similarly, efficacy was not considered in our design, as it does not differ between relevant second-line treatments. ${ }^{9}$

More recently, yet another DCE study on examining patient preference in RA patients was performed by Louder et al. ${ }^{45}$ They conducted a choice-based conjoint survey in biologic-naïve RA patients using a methodology akin to count analysis. Across the seven attributes assessed, route of administration and frequency of administration were among the three most relevant for patient preference. For route of administration, patients mostly preferred oral intake and least favored infusion, so results are thus in line with our findings. Combination with MTX, which turned out to be the second relevant attribute of RA medication in our study, was not assessed in their trial. With regard to frequency of administration, the authors found a linear increase in preferences with lower frequencies, ie, every 8 weeks was most preferred and twice daily was least preferred. Notably, as in Augustovski et $a l,{ }^{43}$ Louder et $\mathrm{al}^{45}$ included costs and efficacy parameters in their design - which we excluded for the reasons mentioned earlier - and did not control for implausible level combinations in their design (eg, "oral intake once every 8 weeks"). Such design differences may well account for the divergent findings relative to our study.

While patient preferences did not markedly change when adjusting for various patient characteristics, adjusted regression analysis still yielded significant influences by patient variables on choices in the DCE. This suggests subgroups with specific preference profiles, despite these groups obviously sharing some highly similar preferences. Future research will examine more thoroughly to what extent individual patient characteristics need to be considered when analyzing preference data.

\section{Conclusion}

In summary the results suggest an oral DMARD that does not have to be combined with MTX and is administered either less or more often than on a weekly basis to be a highly favorable second-line treatment option for patients diagnosed with RA. DMARDs meeting these preferences may increase compliance and adherence in RA, and thus improve health outcomes and quality of life in affected individuals.

\section{Acknowledgments}

The authors want to thank all participating patients and physicians for their valuable input to the study. The authors further want to thank Susanne Wellisch, Pfizer Pharma GmbH, for her great support with her highly appreciated experience.

\section{Disclosure}

This research was funded by Pfizer Pharma GmbH without any other financial activities outside the submitted work. The authors report no other conflicts of interest in this work.

\section{References}

1. Lipsky PE. Rheumatoid arthritis. In: Fauci A, Langford C, editors. Harrison's Rheumatology. New York: McGraw-Hill; 2010:33-42.

2. Lee DM, Weinblatt ME. Rheumatoid arthritis. Lancet. 2001;358(9285): 903-911. 
3. European Musculoskeletal Conditions Surveillance and Information Network. Musculoskeletal Health in Europe: Report v5.0 2012. Available from: http://www.eumusc.net/myUploadData/files/ Musculoskeletal\%20Health\%20in\%20Europe\%20Report\%20v5.pdf. Accessed November 19, 2015.

4. Silman AJ, Hochberg MC. Descriptive epidemiology of rheumatoid arthritis. In: Hochberg MC, Silman AJ, Smolen JS, Weinblatt ME, Weisman MH, editors. Rheumatoid Arthritis. Amsterdam: Elsevier; 2009: $15-22$.

5. Sangha O. Epidemiology of rheumatic diseases. Rheumatology (Oxford). 2000;39(Suppl 2):3-12.

6. Deutsche Rheuma-Forschungszentrum. Daten der Kerndokumentation 2013. Available from: http://dgrh.de/fileadmin/media/Forschung/Versorgungsforschung/ErwachsenenKerndok/Standardpraesentation_2013_ extern.pdf. Accessed November 19, 2015.

7. Smolen JS, Landewé R, Breedveld FC, et al. EULAR recommendations for the management of rheumatoid arthritis with synthetic and biological disease-modifying antirheumatic drugs: 2013 update. Ann Rheum Dis. 2013;73(3):492-509.

8. Singh JA, Saag KG, Bridges SL Jr, et al. 2015 American College of Rheumatology guideline for the treatment of rheumatoid arthritis. Arthritis Rheumatol. 2016;68(1):1-26.

9. Singh JA, Christensen R, Wells GA, et al. Biologics for rheumatoid arthritis: an overview of Cochrane reviews. Sao Paulo Med J. 2013;128(5) 309-310.

10. Yazici Y. Abatacept versus other biologics in methotrexate inadequate responders with rheumatoid arthritis: you like tomato and I like tomahto ... let's call the whole thing off. Arthritis Res Ther. 2012;14(1):104.

11. Casciano R, Malangone E, Ramachandran A, Gagliardino JJ. A quantitative assessment of patient barriers to insulin. Int J Clin Pract. 2011; 65(4):408-414.

12. Fallowfield L, Atkins L, Catt S, et al. Patients' preference for administration of endocrine treatments by injection or tablets: results from a study of women with breast cancer. Ann Oncol. 2006;17(2):205-210.

13. Mohr DC, Boudewyn AC, Likosky W, Levine E, Goodkin DE. Injectable medication for the treatment of multiple sclerosis: the influence of self-efficacy expectations and injection anxiety on adherence and ability to self-inject. Ann Behav Med. 2001;23(2):125-132.

14. Barber N, Parsons J, Clifford S, Darracott R, Horne R. Patients' problems with new medication for chronic conditions. Qual Saf Health Care. 2004; 3(3):172-175.

15. Glombiewski JA, Nestoriuc Y, Rief W, Glaesmer H, Braehler E. Medication adherence in the general population. PLoS One. 2012;7(12) e50537.

16. Pasma A, van't Spijker A, Hazes JM, Busschbach JJ, Luime JJ. Factors associated with adherence to pharmaceutical treatment for rheumatoid arthritis patients: a systematic review. Semin Arthritis Rheum. 2013; 43(1):18-28.

17. van den Bemt BJ, Zwikker HE, van den Ende CH. Medication adherence in patients with rheumatoid arthritis: a critical appraisal of the existing literature. Expert Rev Clin Immunol. 2012;8(4):337-351.

18. Barton JL. Patient preferences and satisfaction in the treatment of rheumatoid arthritis with biologic therapy. Patient Prefer Adherence. 2009;3:335-344.

19. Chilton F, Collett RA. Treatment choices, preferences and decisionmaking by patients with rheumatoid arthritis. Musculoskeletal Care. 2008;6(1):1-14.

20. Fraenkel L, Bogardus S, Concato J, Felson D. Unwillingness of rheumatoid arthritis patients to risk adverse effects. Rheumatology (Oxford). 2002;41(3):253-261.

21. Goekoop-Ruiterman YP, de Vries-Bouwstra JK, Allaart CF, et al. Patient preferences for treatment: report from a randomized comparison of treatment strategies in early rheumatoid arthritis (BeSt trial). Ann Rheum Dis. 2007;66(9):1227-1232.

22. Lempp H, Hofmann D, Hatch SL, Scott DL. Patients' views about treatment with combination therapy for rheumatoid arthritis: a comparative qualitative study. BMC Musculoskelet Disord. 2012;13:200.
23. Scarpato S, Antivalle M, Favalli EG, et al. Patient preferences in the choice of anti-TNF therapies in rheumatoid arthritis: results from a questionnaire survey (RIVIERA study). Rheumatology (Oxford). 2010;49(2):289-294.

24. Willeke P, Becker H, Wassenberg S, Pavenstädt H, Jacobi AM. Bewertung einer Infusionbehandlung der rheumatoiden Arthritis durch Patienten und Rheumatologen [Patient/rheumatologist evaluation of infusion treatment for rheumatoid arthritis]. Z Rheumatol. 2011;70(3):232-234, 236-238. German.

25. Flynn TN, Louviere JJ, Peters TJ, Coast J. Best-worst scaling: what it can do for health care research and how to do it. J Health Econ. 2007; 26(1):171-189.

26. Potoglou D, Burge P, Flynn T, et al. Best-worst scaling vs. discrete choice experiments: an empirical comparison using social care data. Soc Sci Med. 2011;72(10):1717-1727.

27. Marley AA, Louviere JJ. Some probabilistic models of best, worst, and best-worst choices. J Math Psychol. 2005;49:464-480.

28. Deutsche Gesellschaft für Rheumatologie. Berlin: Rheuma in Zahlen: Betroffene Menschen in Deutschland. 2008. Available from: http://grh. de/fileadmin/media/Die_DGRH/Presse/Rheuma_in_Zahlen_presse_ aktual.pdf. Accessed November 19, 2015.

29. Federov V. Theory of Optimal Experiments. New York: Academic Press; 1972.

30. Johnson FR, Lancsar E, Marshall D, et al. Constructing experimental designs for discrete-choice experiments: report of the ISPOR Conjoint Analysis Experimental Design Good Research Practices Task Force. Value Health. 2013;16(1):3-13.

31. Leeb BF, Haindl PM, Maktari A, Nothnagl T, Rintelen B. Patientcentered rheumatoid arthritis disease activity assessment by a modified RADAI. J Rheumatol. 2008;35(7):1294-1299.

32. Rintelen B, Haindl PM, Sautner J, Leeb BA, Deutsch C, Leeb BF. The rheumatoid arthritis disease activity index-5 in daily use: proposal for disease activity categories. J Rheumatol. 2009;36(5):918-924.

33. Horne R, Weinman J, Hankins M. The Beliefs about Medicines Questionnaire: the development and evaluation of a new method for assessing cognitive representations of medication. Psychol Health. 1999;14(1):1-24.

34. Horne R, Weinman J. Patients' beliefs about prescribed medicines and their role in adherence to treatment in chronic physical illness. J Psychosom Res. 1999;47(6):555-567.

35. Neame R, Hammond A. Beliefs about medications: a questionnaire survey of people with rheumatoid arthritis. Rheumatology (Oxford). 2005;44(6):762-767.

36. Anderson J, Caplan L, Yazdany J, et al. Rheumatoid arthritis disease activity measures: American College of Rheumatology recommendations for use in clinical practice. Arthritis Care Res (Hoboken). 2012 64(5):640-647.

37. Clifford S, Barber N, Horne R. Understanding different beliefs held by adherers, unintentional nonadherers, and intentional nonadherers: application of the necessity-concerns framework. J Psychosom Res. 2008; 64(1):41-46.

38. Finn A, Louviere JJ. Determining the appropriate response to evidence of public concern: the case of food safety. J Public Policy Mark. 1992; 11(2):12-25.

39. Auger P, Deevinney TM, Louviere J. Using best-worst scaling methodology to investigate ethical beliefs across countries. $J$ Bus Ethics. 2007;70:299-326.

40. Flynn TN, Louviere JJ, Peters TJ, Coast J. Estimating preferences for a dermatology consultation using best-worst scaling: comparison of various methods of analysis. BMC Med Res Methodol. 2008;8:76.

41. Gesundheitsberichterstattung des Bundes. Das Informations system der Gesundheitsberichterstattung des Bundes. 2014. Available from: http:// www.gbe-bund.de. Accessed November 19, 2015.

42. Skjoldborg US, Lauridsen J, Junker P. Reliability of the discrete choice experiment at the input and output level in patients with rheumatoid arthritis. Value Health. 2009;12(1):153-158.

43. Augustovski F, Beratarrechea A, Irazola V, et al. Patient preferences for biologic agents in rheumatoid arthritis: a discrete-choice experiment. Value Health. 2013;16(2):385-393. 
44. Poulos C, Hauber AB, González JM, Turpcu A. Patients' willingness to trade off between the duration and frequency of rheumatoid arthritis treatments. Arthritis Care Res (Hoboken). 2014;66(7):1008-1015.
45. Louder AM, Singh A, Saverno K, et al. Patient preferences regarding rheumatoid arthritis therapies: a conjoint analysis. Am Health Drug Benefits. 2016;9(2):84-93.

\section{Publish your work in this journal}

Patient Preference and Adherence is an international, peer-reviewed, open access journal that focuses on the growing importance of patient preference and adherence throughout the therapeutic continuum. Patient satisfaction, acceptability, quality of life, compliance, persistence and their role in developing new therapeutic modalities and compounds to optimize clinical outcomes for existing disease states are major areas of interest for the journal. This journal has been accepted for indexing on PubMed Central. The manuscript management system is completely online and includes a very quick and fair peer-review system, which is all easy to use. Visit http://www. dovepress.com/testimonials.php to read real quotes from published authors.

Submit your manuscript here: http://www.dovepress.com/patient-preference-and-adherence-journal 